\title{
PARAMETRIC STUDY OF HEAT AFFECTED ZONE (HAZ) WIDTH IN LASER MICRO- DRILLING OF COPPER SHEET
}

\begin{tabular}{|c|c|c|c|}
\hline B. Chatterjee & K. K. Mandal & A. S. Kuar & S. Mitra \\
P.G.Scholar & Production Engg. Deptt., & Production Engg. Deptt., & Production Engg. Deptt., \\
J.U., Kol.-32. \\
Enool of Laser Science \& & J.U., Kol.-32. & J.U., Kol. - 32. \\
Engineering & Kajal_mandal@email.com & askuar@rediffmail.com & $\begin{array}{l}\text { mail.souren.mitra@gmail.co } \\
\text { J.U., Kol. - 32. }\end{array}$ \\
\hline
\end{tabular}

\begin{abstract}
Copper has excellent electrical and thermal conductivity, good strength and formability. It also exhibits outstanding resistance to corrosion and fatigue. Due to these properties they are used in micro-electronics, robotics, printed circuit board, bio-medical equipments, etc. Laser beam machining is an advanced material processing technique which can be applied for almost all materials. Nowadays there is an increasing trends towards miniaturization of the various components, which requires micro-machining. Use of laser micro-drilling can be attributed to several advantages like high standard of finishing, high production rate, no mechanical damage or tool wear, low material wastage, low production cost, small heat affected zone and ecologically clean technology. In the present research work, $0.2 \mathrm{~mm}$ thick copper sheet is microdrilled by using $\mathrm{Nd}: \mathrm{YVO}_{4}$ laser of maximum power $12 \mathrm{~W}$. HAZ width has been investigated with respect to different processing parameters e.g. laser beam power, pulse frequency, scanning speed and number of pass. The results show that HAZ width increases with the increase of laser beam power throughout the range; it decreases first then increases with the increase of pulse frequency. Whereas, HAZ width increases initially but later decreases with the increase of scanning speed and number of passes. ANOVA and confirmation test has been performed to optimize the HAZ width.
\end{abstract}

Keywords - Laser beam micro-drilling; copper sheet; HAZ width; ANOVA; confirmation test.

\section{INTRODUCTION}

In our everyday life copper \& copper alloys are extensively used in a variety of products. They have excellent electrical and thermal conductivity, good strength and formability. It also has outstanding resistance to corrosion and fatigue. Due to these properties they are used in microelectronics, robotics, aerospace, printed circuit board, biomedical equipments, etc. Laser beam machining (LBM) is a thermal energy based non-conventional machining process in which the material is removed by melting, vaporization, and chemical degradation. LBM can be applied to a wide range of materials like metals, non-metals, difficult-to-machine materials, composites and ceramics for various manufacturing processes like, cutting, drilling, micro-machining, welding, sintering and heat treatment.

The applications of Nd:YAG laser in material processing like trimming, marking, repairing, welding and cutting for electronic industries are presented by $\mathrm{K}$. Washio [1]. Aluminum foils of thickness ranging from 1.5 to $50 \mu \mathrm{m}$, and $\mathrm{Mo}, \mathrm{Cu}, \mathrm{Fe}, \mathrm{Ag}, \mathrm{Au}$, and $\mathrm{Pb}$ foils of $25 \mu \mathrm{m}$ thickness have been drilled with femtosecond Ti-sapphire laser pulses centered at $800 \mathrm{~nm}$ by X. Zhu et al and examined the influence of laser parameters and material properties on hole drilling processes at sub-10 $\mu \mathrm{m}$ scale [2]. Laser machining is an attractive alternative to traditional machining of Al 2024 because critical operation parameters in aeronautic industry like processing time, versatility, contamination and finish can be improved. D. Arau'jo et al observed a heat affected zone (HAZ) extension lower than $5 \mathrm{~mm}$ for Al 2024 [3]. Laser processing at shorter wavelengths reduces the reflectivity of the workpiece to the incident laser radiation. L. Tunna et al reviewed the limiting factors in the micro machining of aluminium using a diode pumped solid state (DPSS) Nd:YAG laser [4]. A. Stournaras et al investigated experimentally the quality of laser cutting of aluminum alloy Al5083 using a pulsed $\mathrm{CO}_{2} 1.8 \mathrm{~kW}$ laser cutting system. The quality of the cut had been monitored by measuring the kerf width, and the size of the heat-affected zone [5]. A. Riveiro et al observed that the pulsed laser cutting of copper-aluminium alloys can be optimized using a cutting head assisted by an off-axis supersonic nozzle to remove the molten material and selecting the adequate processing parameters. Quality criteria had shown the possibility to obtain cuts with lower width, average roughness, dross, and with a minimum HAZ [6]. Laser hole cutting in bronze was carried out by B.S. Yilbas et al and the thermal stress formed in the cutting section was examined using a finite element method. It was found that the high conductivity of bronze increases the cooling rates within the cutting section, which influences the thermal stress field in the cutting region [7]. A. Riveiro et al presented a study on the influence of different assist gases (argon, nitrogen, oxygen and air) on the edge quality and its surface chemistry during laser cutting of a typical Al-Cu alloy [8]. Klaus Hock et all presented a comparison between remote laser cutting by a fiber laser and water-jet guided laser cutting using a $532 \mathrm{~nm}$ solid state laser. Complex contours are proposed in brass sheets (thickness less than $100 \mu \mathrm{m})$. It was observed that dross free cuts with almost no HAZ and small kerf width was obtained for the water-jet guided process, whereas small dross, notable heat affected zone and varying kerf width was noticed for remote cutting [9]. S. Misra et al developed a prediction model and optimize for laser beam percussion drilling of thin aluminum sheet by using pulsed Nd:YAG laser with an average power of $200 \mathrm{~W}$, pulse width of $0.5-4 \mathrm{~ms}$, pulse frequency of $10-25 \mathrm{~Hz}$ [10].

In the present research, $800 \mu \mathrm{m}$ diameter through hole was made on a reflective copper sheet of $0.2 \mathrm{~mm}$ thickness by $\mathrm{Nd}: \mathrm{YVO}_{4}$ (EMS 100) laser . L9 Orthogonal Array has been utilized as the design of experiment tool. Taguchi method is applied for optimization of HAZ width and thereby selecting the optimum combination of process parameters. Finally the predicted optimum results have been verified by performing the confirmation tests.

\section{EXPERIMENTAL PLANNING}

Copper sheet of thickness $0.2 \mathrm{~mm}$ is used as the workpiece for the experimental investigation. Major properties of copper are shown in Table I. Fig. 1, shows the scheme of micro- 
drilling operation. A typical solid state laser, Nd:YVO $($ EMS 100) of maximum laser beam power of $12 \mathrm{~W}$, wavelength of $1064 \mathrm{~nm}$ is utilized for laser micro-drilling operation. The laser system has three main parts i.e. laser unit, control unit and work station as shown in Fig. 2. The laser unit consists of EMS 100 laser marker compatible with Scorpion Rapid and Raptor Laser. The control unit consists of OFF/ON switch, device for setting the process parameters. A working station is used for placing and aligning the workpiece for the operation.

In the present research, four processing parameters i.e. laser beam power (L.P.), pulse frequency (P.F.), scanning speed (S.S.) and number of passes (N.P.) with three levels each are considered as the input parameters to investigate their effect on the response i.e. HAZ width (output parameter). Detail of the process parameters are shown in Table II.

TABLE I. MAJOR PROPERTIES OF COPPER

\begin{tabular}{|c|c|c|}
\hline Properties & Unit & Value \\
\hline Electrical Conductivity & Siemens/mm & 58.5 \\
\hline Thermal Conductivity & $\mathrm{W} / \mathrm{mK}$ & 390 \\
\hline Density & $\mathrm{gm} / \mathrm{cc}$ & 8.96 \\
\hline Yield Strength & $\mathrm{Mpa}$ & 70 \\
\hline Ultimate Tensile Strength & $\mathrm{Mpa}$ & 220 \\
\hline Melting Point & Degree Celcious & 1084 \\
\hline
\end{tabular}

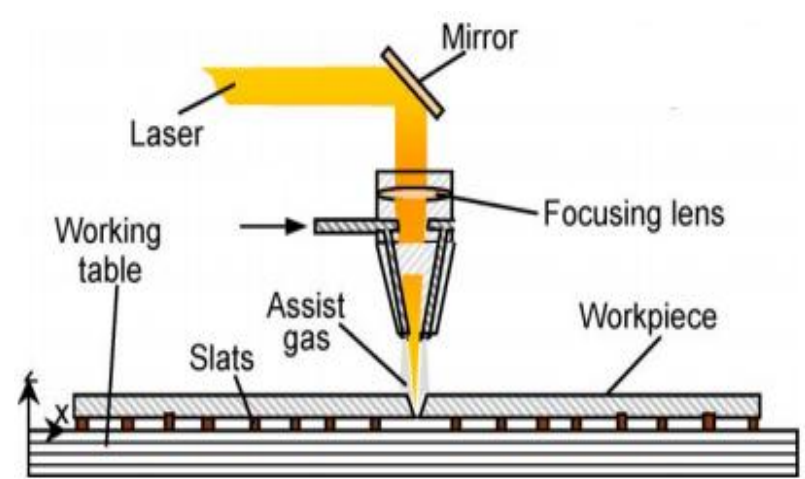

Fig. 1. Scheme of Laser Micro-drilling Operation

TABLE II.

DETAIL OF PROCESS PARAMETERS

\begin{tabular}{|c|c|c|c|c|}
\hline Parameters & Unit & Level 1 & Level 2 & Level 3 \\
\hline Laser Beam Power & Watt & 8.4 & 9.6 & 10.8 \\
\hline Pulse Frequency & $\mathrm{kHz}$ & 6 & 9 & 12 \\
\hline Scanning Speed & $\mathrm{mm} / \mathrm{sec}$ & 0.2 & 0.4 & 0.6 \\
\hline Number of Pass & & 5 & 7 & 9 \\
\hline
\end{tabular}

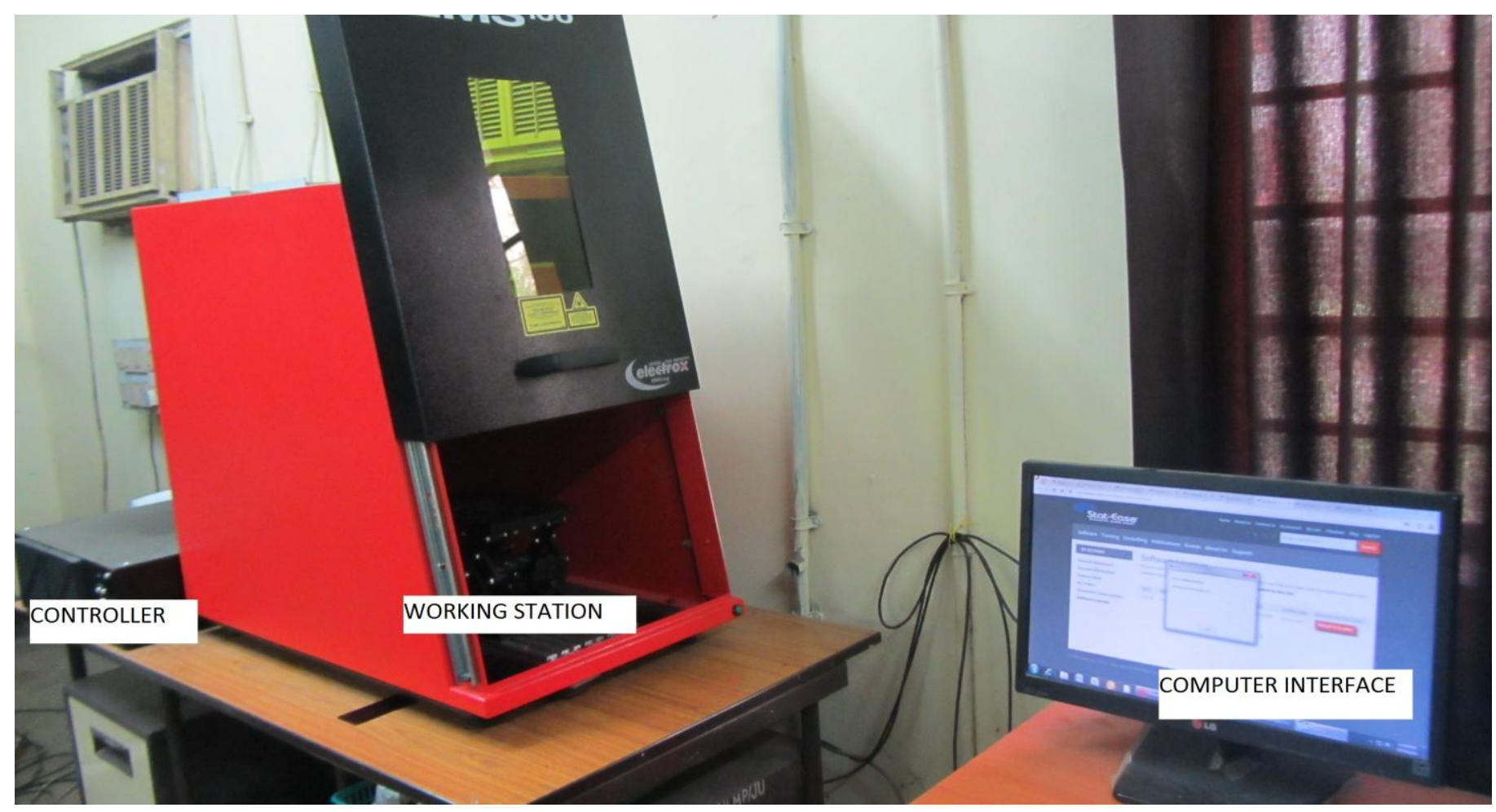

Fig. 2. Experimental Set-up for Laser Micro-drilling 


\section{EXPERIMENTAL RESULTS}

After completion of the set of experiments, top diameter of hole and heat affected zone (HAZ) diameter are measured very carefully with the help of optical microscope (Olympus ST6). From these observed data HAZ width (w) is calculated using the equation (1), and the corresponding values are displayed in Table III. It also displays the corresponding Signal to Noise $(\mathrm{S} / \mathrm{N})$ ratios. One of the photographic views under the optical microscope of the micro-drilled hole is shown in Fig. 3.

$w=\frac{\text { HAZ Diameter }- \text { Top Diameter }}{2}$

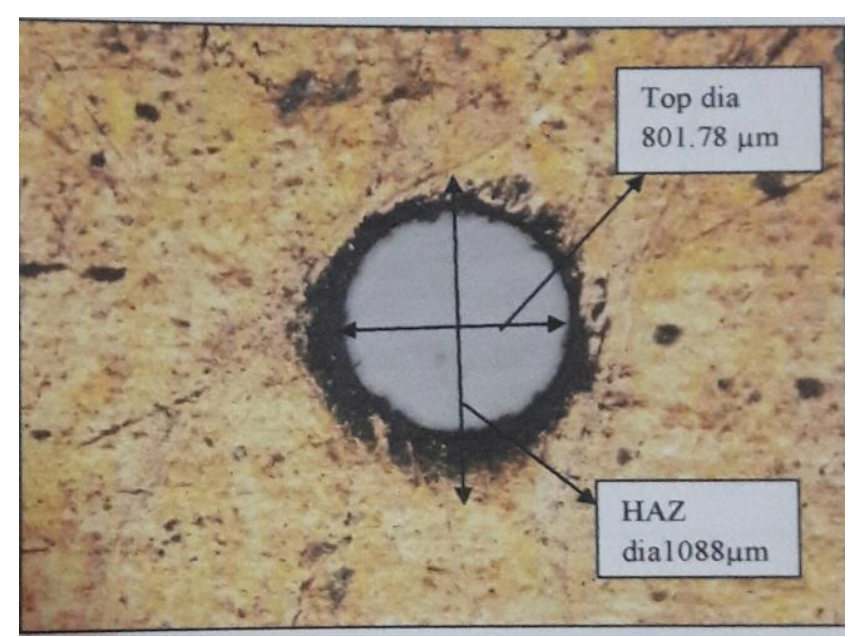

Fig. 3. Photographic View of the Micro-drilled Hole

TABLE III.

EXPERIMENTAL RESULTS AND S/N RATIOS

\begin{tabular}{|c|c|c|c|c|c|c|c|c|}
\hline $\begin{array}{c}\text { Expt. } \\
\text { No. }\end{array}$ & $\begin{array}{c}\text { Laser Beam } \\
\text { Power (Watt) }\end{array}$ & $\begin{array}{c}\text { Pulse Frequency } \\
(\mathbf{k H z})\end{array}$ & $\begin{array}{c}\text { Scanning Speed } \\
(\mathbf{m m} / \mathbf{s e c})\end{array}$ & $\begin{array}{c}\text { Number of } \\
\text { Pass }\end{array}$ & $\begin{array}{c}\text { HAZ Dia. } \\
(\mathbf{m m})\end{array}$ & $\begin{array}{c}\text { Top Diameter of } \\
\text { Hole }(\mathbf{m m})\end{array}$ & $\begin{array}{c}\text { HAZ Width } \\
(\boldsymbol{\mu m})\end{array}$ & $\begin{array}{c}\text { S/N } \\
\text { Ratio }\end{array}$ \\
\hline 1 & 8.4 & 6 & 0.2 & 5 & 0.9627 & 0.8118 & 75.45 & -37.5532 \\
\hline 2 & 8.4 & 9 & 0.4 & 7 & 0.9869 & 0.8222 & 82.35 & -38.3133 \\
\hline 3 & 8.4 & 12 & 0.6 & 9 & 0.972 & 0.8125 & 79.75 & -38.0346 \\
\hline 4 & 9.6 & 6 & 0.4 & 9 & 1.0134 & 0.8208 & 96.30 & -39.6725 \\
\hline 5 & 9.6 & 9 & 0.6 & 5 & 0.9701 & 0.8123 & 78.90 & -37.9415 \\
\hline 6 & 9.6 & 12 & 0.2 & 7 & 1.0298 & 0.8186 & 105.6 & -40.4733 \\
\hline 7 & 10.8 & 6 & 0.6 & 7 & 1.0317 & 0.8158 & 107.9 & -40.6645 \\
\hline 8 & 10.8 & 9 & 0.2 & 9 & 1.0213 & 0.8199 & 100.7 & -40.0606 \\
\hline 9 & 10.8 & 12 & 0.4 & 5 & 1.0352 & 0.8236 & 105.8 & -40.4897 \\
\hline
\end{tabular}

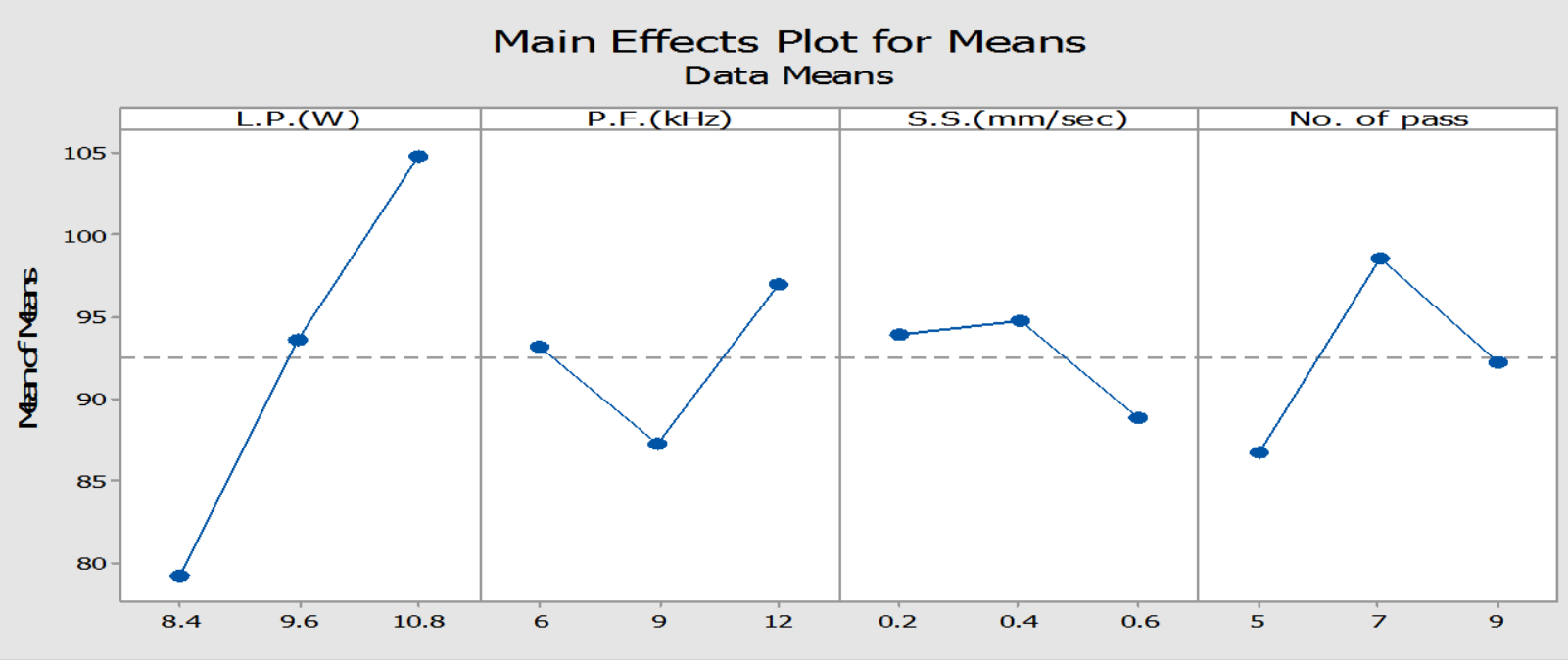

Fig. 4. Main Effects plot of the Mean 


\section{EFFECTS OF PROCESS PARAMETERS ON HAZ WIDTH}

The main effects plot for Means of the process parameters on HAZ width are shown in Fig. 4. It is drawn with the help of the Minitab Software using Taguchi analysis.

It is observed from the main effects plot that HAZ width increases uniformly with the increase of laser beam power. Because more the laser beam power more will be heat input to the drilled region and more will be the material melting and vaporization from the top surface. Due to the excess of heat input than the requirement for proper drilling, more HAZ is formed and spread around the drilling region..

Initially HAZ width decreases with the increase of pulse frequency because duration of heat input is decreased and most of the heat is utilized for drilling which results less chance for HAZ formation. But it increases uniformly with the further increase of pulse frequency due to the excess heating at the top compared to the heat conduction which tends to formation of HAZ.

HAZ width increases slowly at the initial stage, but it decreases again very fast with the further increase of scanning speed beyond that value. Because at the initial stage heat input is more than the requirement for proper drilling. After a certain value heat input becomes insufficient as the duration of heat input is decreased and there is a less chance for the formation of HAZ.

Also, HAZ width increases initially however it decreases again uniformly with the increase of number of pass. Reason is that due to the increase of number of pass, duration of heat input is increases rapidly due to repeated heating effect at the top surface, so the excess heat may not be conducted too fast.
Whereas further increase of number of pass may not affect too much as it is already drilled and the excess heat can be passed away through the hole.

The plot for Means show that optimal combination of input parameters for minimization of HAZ width is obtained at the lowest value of means of HAZ width which is observed at laser beam power of 8.4 Watts, pulse frequency of $9 \mathrm{kHz}$, scanning speed of $0.6 \mathrm{~mm} / \mathrm{sec}$ and number of pass of 5 .

The main effects plot for $\mathrm{S} / \mathrm{N}$ Ratio of the process parameters on HAZ width are shown in Fig. 5, which are drawn with the help of Minitab Software using Taguchi analysis. As the HAZ width is concerned, so 'smaller is better' option is selected. The plot also shows that optimal combination of input parameters for minimization of HAZ width is at laser beam power of 8.4 Watts, pulse frequency of $9 \mathrm{kHz}$, scanning speed of $0.6 \mathrm{~mm} / \mathrm{sec}$ and number of pass of 5 .

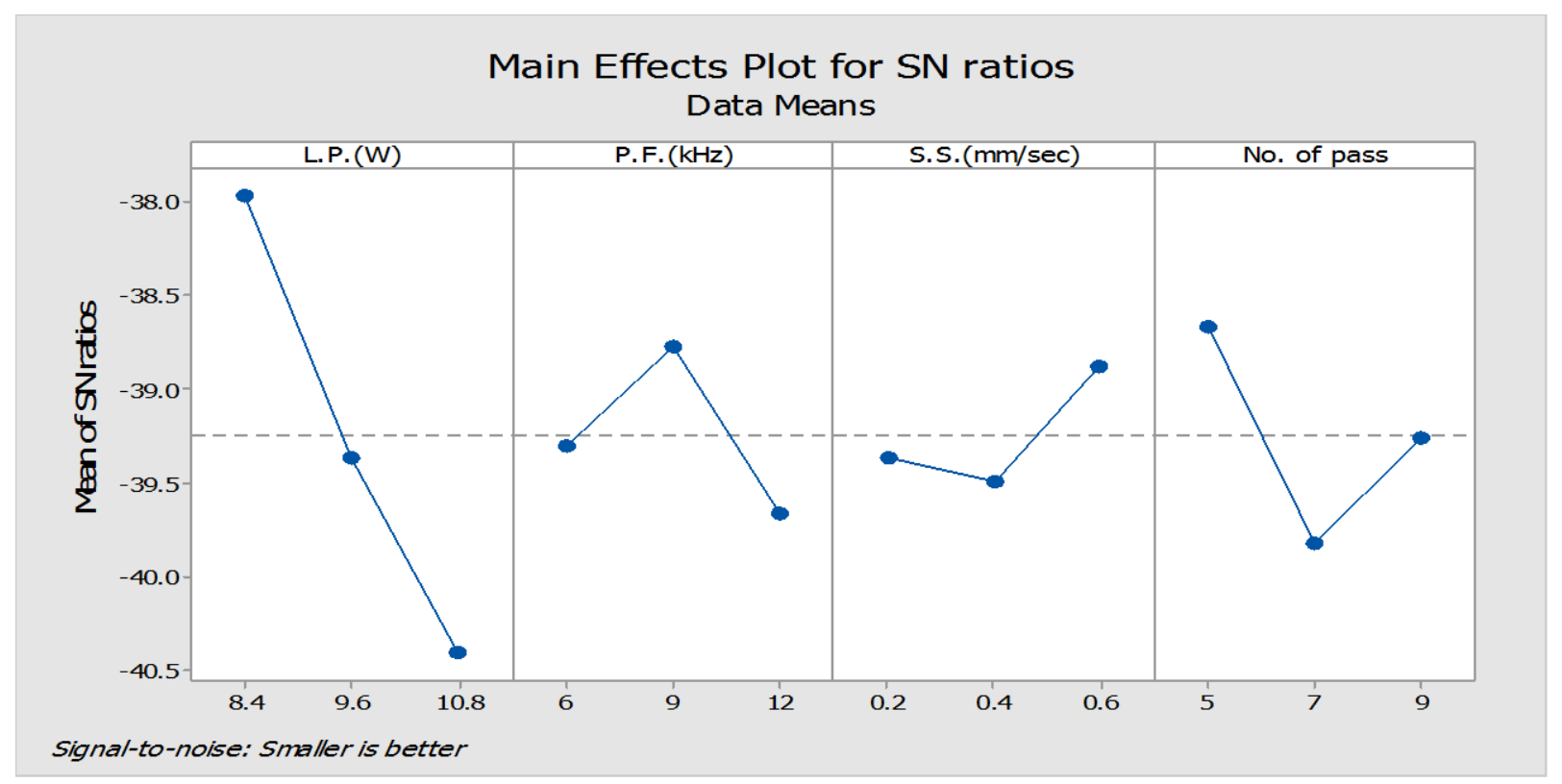

Fig. 5. Main Effects plot of the S/N Ratio 


\section{ANALYSIS OF VARIANCE OF HAZ WIDTH}

Analysis of Variance (ANOVA) of experimental data is carried out to identify the significant drilling parameters influencing the HAZ width. The results of ANOVA are shown in Table IV by comparing the F-test value of the process parameters. The total sum of square deviation can be determined from the formula [11] in equation 2.

$$
S S T=\sum_{j=1}^{W}\left(\eta_{j}-\eta_{m}\right)^{2}
$$

Where $\mathrm{N}$ is the No. of experiments, $\eta_{m}$ is the grand mean of all the $\mathrm{S} / \mathrm{N}$ ratios, which is $-39.2448(\mathrm{~dB})$ in this experiment. The calculated SST value is used to determine the relative influence of the factors. Now, the sum of squares due to the factor like, laser beam power which is equal to the total squared deviation of the wave for that factor from line representing the overall mean. There are three experiments for every level. So, the sum of squares due to laser beam power is calculated as [11] using equation 3 .

$$
3\left(\eta_{L P_{1}}-\eta_{m}\right)^{2}+3\left(\eta_{L P_{2}}-\eta_{m}\right)^{2}+3\left(\eta_{L P_{g}}-\eta_{m}\right)^{2}
$$

Where, $\eta_{L P_{1}}$ is the mean of $\mathrm{S} / \mathrm{N}$ ratio for LP at level 1 . In this way same will be calculated for other parameters. Mean squares are determined by dividing these sum squares by degrees of freedom. After then percentage contribution of individual factors are calculated. It can be concluded from ANOVA result (Table IV) that the process parameters like, laser beam power has the greatest percentage of contribution; so it is the most significant, whereas number of pass and pulse frequency have lesser percentage of contribution; so they are less significant. On the other hand scanning speed has the least percentage of contribution; so it is the most insignificant. Here, residual error is zero.

TABLE IV

ANOVA RESULT

\begin{tabular}{|c|c|c|c|c|c|c|}
\hline Source & DF & Sum of Squares & Mean Squares & F-Value & Percentage Contribution & Rank \\
\hline Laser Beam Power & 2 & 8.9773 & 4.4887 & 14.4006 & 70.05 \\
\hline Pulse Frequency & 2 & 1.2112 & 0.6056 & 1.9428 & 9.45 \\
\hline Scanning Speed & 2 & 0.6233 & 0.3117 & 1.0 & 4.86 \\
\hline Number of Pass & 2 & 2.0036 & 1.0018 & 3.2139 & 15.63 \\
\hline Error (Pulled) & 2 & 0.6233 & 0.3117 & & & \\
\hline Total & 8 & 12.8154 & & & & \\
\hline
\end{tabular}

\section{VERIFICATION (CONFIRMATION) EXPERIMENT}

After determining the optimum conditions and predicting the response under these conditions, final step is to predict and verify the adequacy of the additive model for determining the optimum quality characteristics. The predicted optimum value of $\mathrm{S} / \mathrm{N}$ ratio is calculated from the relationship given below in equation 4 , [11].

$$
\eta_{o p t}=\eta_{m}+\sum_{j=1}^{p}\left(\eta_{j}-\eta_{m}\right)
$$

Where, $\eta_{j}$ is the mean $\mathrm{S} / \mathrm{N}$ ratio at the optimum level of the individual parameter, $\eta_{\mathrm{m}}$ is the grand mean $\mathrm{S} / \mathrm{N}$ ratio at all the levels of the parameters under experimentation and $p$ is the number of main design parameters that affect the quality characteristics. The predicted optimum value obtained is $36.9107(\mathrm{~dB})$. So the corresponding predicted value of HAZ width (mean) will be $70.07 \mu \mathrm{m}$. The calculated error variance

is $0.3117(\mathrm{~dB})^{2}$. The corresponding two-standard deviation confidence limits for prediction error of the $\mathrm{S} / \mathrm{N}$ ratio for $\mathrm{HAZ}$ width are \pm 1.1166 .

Experiments with optimum parameter settings are done and compared the observed value (average) with the predicted value. In this case the optimum process parameters are laser beam power of 8.4 Watts, pulse frequency of $9 \mathrm{kHz}$, scanning speed of $0.6 \mathrm{~mm} / \mathrm{sec}$ and number of pass of 5 and the predicted value of HAZ width (mean) is $70.0701 \mu \mathrm{m}$. The experimental value of HAZ width (mean) under the same specified optimum combination of process parameters obtained is $67.1902 \mu \mathrm{m}$. The corresponding $\mathrm{S} / \mathrm{N}$ ratio value is -36.5461(dB). Result shows both the values are closer to each other and within the confidence limits. Hence it may be concluded that the additive model is adequate for describing the dependence of response on the various parameters. Detail of the verification experiment is shown in Table $\mathrm{V}$.

TABLE V. VERIFICATION OF TEST RESULTS

\begin{tabular}{|c|c|c|}
\hline & Predicted Optimum & Actual Optimum \\
\hline Level & $\mathrm{LP}_{1} \mathrm{PF}_{2} \mathrm{SS}_{3} \mathrm{NP}_{1}$ & $\mathrm{LP}_{1} \mathrm{PF}_{2} \mathrm{SS}_{3} \mathrm{NP}_{1}$ \\
\hline HAZ Width $(\mu \mathrm{m})$ & 70.0701 & 67.1902 \\
\hline S/N Ratio $(\mathrm{dB})$ & -36.9107 & -36.5461 \\
\hline $\begin{array}{c}|c| \\
\text { Predicted Error of } \\
\text { S/N Ratio }(\mathrm{dB})\end{array}$ & \multicolumn{2}{|c|}{ \pm 1.11646} \\
\hline Confidence Limits & \multicolumn{2}{|c|}{ \pm} \\
\hline
\end{tabular}




\section{Acknowledgment}

This work was supported in part by a grant from the TEQIP Phase II at Jadavpur University. All the experimental work were performed in School of Laser Science \& Engineering, Jadavpur University.

\section{Conclusions}

It is concluded from main effects plot for Means and S/N Ratio that HAZ width increases continuously with the increase of laser beam power for all the levels of other process parameters. HAZ width first decreases and then increases with the increase of pulse frequency. In other cases, HAZ width first increases and then decreases with the increase of scanning speed and number of pass. However, the most influencing factor is the laser beam power as it controls the non-uniform vaporization from the top surface relative to the bottom surface and the least influencing factor is the scanning speed. It is also observed that optimal combination of input parameters for minimization of HAZ width is obtained at laser beam power of 8.4 Watts, pulse frequency of $9 \mathrm{kHz}$, scanning speed of $0.6 \mathrm{~mm} / \mathrm{sec}$ and number of pass of 5 .

\section{References}

[1] K. Washio, "Neodymum -doped solid-state lasers and thier applications to materials", Materials chemistry and Physics, vol. 31, pp. $51-66$, 1992.

[2] X. Zhu, D.M. Villeneuve, A.Yu. Naumov, S. Nikumb, P.B. Corkum, "Experimental study of drilling sub-10 $\mu \mathrm{m}$ holes in thin metal foils with femtosecond laser pulses", Applied Surface Science, vol. 152, pp. 138 $148,1999$.

[3] D. Arau'jo, F.J. Carpio,D.Me'ndez, A.J. Garcı 'a, M.P. Villar, R. Garcı'a, D. Jime 'nez, L. Rubio, "Microstructural study of CO2 laser machined heat affected zone of 2024 aluminum alloy", Applied Surface Science, vol. 208-209, pp. 210-217, 2003.

[4] L. Tunna, W. O'Neill, A. Khan, C. Sutcliffe, "Analysis of laser micro drilled holes through aluminium for micro-manufacturing applications", Optics and Lasers in Engineering, vol. 43, pp. 937-950, 2005.

[5] A. Stournaras, P. Stavropoulos, K. Salonitis, G. Chryssolouris, "An investigation of quality in $\mathrm{CO}_{2}$ laser cutting of aluminum", CIRP Journal of Manufacturing Science and Technology, vol. 2, pp. 61-69, 2009.

[6] A. Riveiro, F. Quintero, F. Lusqui nos, R. Comesa na, J. Pou, "Effects of processing parameters on laser cutting of aluminium-copper alloys using off-axial supersonic nozzles”, Applied Surface Science, vol. 257, pp. 5393-5397, 2011.

[7] B. S. Yilbas, S.S. Ahktar, C. Chatwin, "Laser hole cutting into bronze: Thermal stress analysis", Optics \& Laser Technology, vol. 43, pp. 11191127, 2011.

[8] A. Riveiro, F. Quintero, F. Lusquiños, R. Comesaña, J. del Val, J. Pou, "The Role of the Assist Gas Nature in Laser Cutting of Aluminum Alloys", Physics Procedia, vol. 12, pp. 548-554, 2011.

[9] K. Hock, B. Adelmann, R. Hellmann, "Comparative study of remote fiber laser and water-jet guided laser cutting of thin metal sheets", Physics Procedia, vol. 39, pp. 225 - 231, 2012.

[10] S. Misra, V. Yadava, "Modelling and optimization of laser beal percussion drilling of thin aluminim sheet”, Optics \& Laser Technology, vol. 48, pp. $461474,2013$.

[11] M. S. Phadke, Quality Engineering using Robust Design, Prentice Hall: Englewood Cliffs, 1989. 